\title{
Enjoyment of eLearning Among Teacher Education Students in Australia
}

\author{
Jennifer Rowley ${ }^{1}$, Jennifer O’Dea ${ }^{2}$ \\ ${ }^{1}$ Sydney Conservatorium of Music, ${ }^{2}$ Faculty of Education and Social Work \\ The University of Sydney, Sydney, NSW, 2006, Australia
}

Tel: 61-293-511-328. E-mail: jennifer.rowley@sydney.edu.au

Jennifer Rowley (Corresponding author)

Sydney Conservatorium of Music, The University of Sydney

Building C41, Sydney, 2006 NSW, Australia

Tel: 61-293-511-328. E-mail: jennifer.rowley@sydney.edu.au

Received: December 19, 2013 Accepted: January 10, 2014 Published: January 15, 2014

doi:10.5296/ire.v2i1.4794

URL: http://dx.doi.org/10.5296/ire.v2i1.4794

\begin{abstract}
The major research question for this study was -"How do students perceive the enhancement of their own learning through use of eLearning?" The study investigated student teacher's enjoyment and perceptions of eLearning and how it is enhanced by their use of various eLearning activities - particularly the discussion board. Participants were undergraduate teacher education students who were undertaking a course at the University of Sydney, Australia. Methods included a qualitative examination using focus groups, open-ended written answers and a thematic content analysis of focus group transcripts to investigate how students perceived their learning to be enhanced. Twelve major themes identified how eLearning enhanced perceived student learning. The results revealed that eLearning was found to: facilitate broader and deeper learning; provide a resource management and organisation system; allow 24 hour access and flexibility; facilitate interaction and communication with peers; enable students to work and learn at their own pace; provide a place for students to find advice, tips and assistance; and provide a site for anonymous study-related and social interaction. Positive comments related to the stimulation of thought, discussion, debate and interaction via online discussion boards. Students identified learning
\end{abstract}


from other students' differing opinions, being enabled to more deeply contextualize and further analyse helped them to develop an understanding of the content material being covered.

Keywords: curriculum, eLearning, asynchronous discussion, teacher education, higher education, discussion boards

\section{Introduction}

A student's perception of their own learning in an online learning environment (OLE) is one of enjoyment and ease (Palmer \& Holt, 2009). Students in higher education today require a blend of assessment tasks, tutorial discussion and lectures in a technology and a collaboratively rich environment, as this mix of technology, pedagogy and design results in more effective learning (Akanbi, 2000; Ellis, Goodyear, O'Hara \& Prosser, 2007; Long, 2005). Of benefit to today's university teacher is that eLearning can provide appropriate learning for the $21^{\text {st }}$ century student whilst modeling appropriate teaching practices. Enhancing eLearning environments is a strategic goal of many university administrators as there is evidence showing students prefer to learn using technologies. University's who train the next generation of teachers are faced larger enrolments and the expectation of providing cutting edge pedagogy. There is an additional requirement today to implement eLearning in teacher education so that the beginning teacher can implement similar strategies within their own classroom environment. It is recognised, therefore, that teacher education graduates require experience in using eLearning tools and strategies to be adequately prepared for today's school classroom. Technology advances create a teaching and learning environment in which teacher educators can utilise the available technology to enhance their programs and to streamline delivery of the course content (Taylor, Dunbar-Hall, \& Rowley, 2012). The focus of the study described in this paper was to investigate how the teacher education undergraduates perceive eLearning with a focus on their enjoyment of discussion boards.

\section{Integrating eLearning into Curricula}

The integration of eLearning into university curricula is one that often presents unique challenges and stressors to teacher educators (Ferfolja, 2008; Murray-Harvey, 1999) and therefore, demands better support, as it is critical for the enhancement of pre-service teachers' learning. In Australia, as in many countries worldwide, ICT is a mandatory component of pre-service teacher education programs (Whitton, Sinclair, Barker, Nanlohy, \& Nosworthy, 2010), and is acknowledged as a critical component of pre-service teachers' professional training and graduate attributes. eLearning was integrated into two university teacher training program curricula through E-readings, discussion boards, lectures and online assessment tasks to create a blended learning environment for teacher education students. Learning management systems offer significant teaching benefit in the expansion of technology in learning and the reduction of face-to-face teaching time as cohorts of students rapidly expand. The motivation, therefore, to implement eLearning into the teacher training program was similar to the opinion of Long and Ehrmann (2005) who challenge the current tertiary learning space and state that "Faculty time is too precious to waste it doing something that a streaming video could do as well or better" (Long \& Ehrmann, 2005, p. 50). 
Reported benefits of eLearning to students have been somewhat, but not thoroughly examined in previous research. Such research supports that eLearning enables the pre-service teacher to alleviate anxiety and feelings of isolation from university teachers and peers as the technology enables learning and communication to occur asynchronously, enabling the pre-service teachers to interact and collaborate with peers and academics anywhere and at anytime (Garrison \& Anderson, 2003 as cited in Rowley \& Tindall-Ford, 2008). The motivation to use a combination of face-to-face teaching with online learning can create new opportunities for learning partnerships and can extend the learning community beyond that experienced by students in a University lecture theatre. As Long (2005) suggests, "Recent data showing that pedagogy using 'interactive engagement' methods results in higher learning gains than does the traditional lecture format and is usually accompanied by lower failure rates" (p. 60). The promotion of new ways to communicate, engage in the content, research and develop as an individual are all essential ingredients for well rounded graduates - and, indeed, school teachers.

To develop students' competence as eLearners it is vital to create opportunities for eLearning to be integrated further into existing curriculum and such sites would be useful in addressing the development of graduate attributes through the pre-service teachers' interaction with technology. The three major graduate attributes identified by the University of Sydney, and investigated through the current study, were - commitment to independent learning; critical thinking and development of analysis skills and appreciation of computer-based activities as a part of the learning environment. eLearning sites were initially developed to allow easy access to teaching and learning materials as well as to incorporate quality education through the intellectual and environmental significance of the individual's learning. Quality education, therefore, should be defined here as that which best meets the needs of the students.

Much of the literature on eLearning focuses on the general competence level of students to embrace the technology in an attempt to enhance learning (Bowles, 2004). What is not clear is how the students perceive this medium as an aid to their development as an independent and engaged learner. Dixon, Dixon and Siragusa (2007) found that students perceived learning to be more enjoyable and easier to access in the online learning environment .So, how should eLearning be incorporated into the curriculum? eLearning has the potential to simplify complex communication, to increase the pace of transferring information with a transformation process that has the potential to maximize the effectiveness of the learning intervention (Bowles, 2004). The prospect, therefore, of developing a blended learning environment for teacher education students was determined as successful from previous research that determined that our students were technology ready and literate (Rowley \& Tindall-Ford, 2008). The challenge was to manipulate this technological literacy and interaction with asynchronous discussion boards into an integral part of their teaching program so that learning was enhanced in a meaningful manner.

Tertiary teacher training programs are utilizing Internet based technologies (such as Blackboard/Moodle etc.) to build blended learning communities and to enhance pre-service teachers' learning experiences. Researchers found that pre-service teachers have several concerns including those related to behaviour management, lesson planning and curriculum 
design (Groundwater-Smith, Ewing \& Le Cornu, 2011; Whitton et al., 2010) increasing the popularity of blended learning environments in addressing some challenges in the preparation and support of pre service teachers (Ferfolja, 2008; Holstrom, Ruiz, \& Weller, 2007; Schuck, 2003). "While E-learning activities and materials have a lot to offer, it is reasonable to ask how students experience coherence in their learning activity when it is distributed across both face-to-face and online contexts" (Ellis et al., 2007, p. 84). Research by Ramsden (2003) stated the need for university teachers to develop a connection between student learning and quality teaching. As a part of the development of a blended learning environment, it was important to recognise the commitment that the university has also to the ongoing development of graduate attributes through the students' interaction with and use of technology through eLearning. Heirdsfield, Walker, Tambyah and Beutel (2011) at Queensland University of technology investigated student perception of using the same online learning management system as this study and found increased enjoyment of learning and a greater sense of connection with other students during the learning process. This is an important finding as this study asked students specifically how they perceived the enhancement of their learning though the online learning environment.

\section{Method}

Focus groups were undertaken from the two teacher education programs to assess students' attitudes towards the impact of introducing online forms of course delivery and blended learning using eLearning. The aim of the study was to investigate student perceptions of how their learning was enhanced by their use of eLearning. Both university teacher preparation programs had been recently restructured to incorporate course delivery using blended learning and so focus group questions were framed around exploring how the students used these aspects of eLearning and which, if any, they considered to be most helpful in the enhancement of their learning. The specific features of eLearning that were examined in focus groups included online lectures, quizzes and assignments; online content discussion boards; an online social discussion board and an assignment requiring student postings on an online discussion board. The major research question for this study was therefore, "How do students perceive the enhancement of their own learning and what do they identify as the benefits of using eLearning?" Student responses were all written on a whiteboard, discussed and ranked in a small focus group environment and a research assistant who used shorthand also recorded the discussion verbatim in detail. The full transcripts of the research assistant's notes were analyzed separately by each of the authors and the research assistant using a thematic analysis.

\subsection{Participants}

Participants were undergraduate teacher education students who were undertaking the third year of a course in the Bachelor of Education in Human Movement and Health Education $(n=63)$ or Music Education $(n=61)$ at the University of Sydney, Australia. The qualitative focus group questions were developed from the findings of our previous work (Rowley \& O'Dea, 2009) and the current study focused on examining students' identification and perceptions of any particular benefits to their learning from the eLearning course delivery. 


\subsection{Focus Group Questions}

Students were asked open-ended questions about their needs, expectations, usefulness and the most/least helpful to their learning when using the eLearning activities and what they perceive eLearning could do to enhance their learning. Students' perceived enhancement of eLearning was explored during the regular course evaluation at the conclusion of the coursework. Student responses were ranked in a small research group environment and a research assistant also recorded the discussion for later transcription. The full transcripts were analysed and using a thematic analysis and themes emerged from this analysis are reported in this paper. The study design and protocol were approved by the Faculty as part of the annual course evaluation activities and participant students all gave consent to participate in the research study as an anonymous volunteer.

\section{Results}

The first focus group question asked students to identify the aspects of the eLearning activities that students perceived to enhance their learning the most, if at all. Students were asked, "Do you think that the eLearning components of this subject enhanced your learning? If so, how? If not, how?" The major themes to emerge from the focus groups and student comments are presented below in Table 1.

Table 1. Students' comments about the perceived benefits and enjoyment of elearning and discussion boards among teacher education students in Australia

\begin{tabular}{|c|c|}
\hline Theme & Sample student comments \\
\hline $\begin{array}{l}\text { Resource management and } \\
\text { organisation system }\end{array}$ & $\begin{array}{l}\text { Resources available and models of lesson plans that I can adapt and use for my } \\
\text { own teaching } \\
\text { I think it is much easier to store, access and present information } \\
\text { Easy access to heaps of resources }\end{array}$ \\
\hline $\begin{array}{l}\text { Facilitates interaction and } \\
\text { communication }\end{array}$ & $\begin{array}{l}\text { Great discussions for ideas and opinions } \\
\text { Enabled better communication } \\
\text { Gave chance to interact with others and to gauge what they are struggling with } \\
\text { A different way of communicating and learning at the same time }\end{array}$ \\
\hline $\begin{array}{l}\text { Facilitates and motivates } \\
\text { learning before class }\end{array}$ & $\begin{array}{l}\text { Having the lectures there gave me an opportunity for further thinking } \\
\text { It helped to make sure we were thinking about the subject outside of uni } \\
\text { With the lectures online, as I took notes so I had to go through them } \\
\text { Helped to reinforce learning }\end{array}$ \\
\hline $\begin{array}{l}\text { Discussion board facilitates } \\
\text { broader learning }\end{array}$ & $\begin{array}{l}\text { The discussion boards help to develop ideas...provides: me with opportunities } \\
\text { that I didn't get in class } \\
\text { Having assignments online and discussion issues with others... and learning } \\
\text { from other people's experiences } \\
\text { People could provide feedback on certain topics and give their point of view } \\
\text { enhancing peoples learning } \\
\text { Discussion board and discussion assessments made me have a deeper } \\
\text { understanding of subject and how to apply the things we have learnt }\end{array}$ \\
\hline $\begin{array}{l}\text { Discussion boards reinforce } \\
\text { student confidence }\end{array}$ & $\begin{array}{l}\text { Gives me confidence to talk in tutorials because I have ideas from others } \\
\text { Reading people's opinions and freely communicating }\end{array}$ \\
\hline Storage site for resources & $\begin{array}{l}\text { Having readings, resources (like lesson plans) and lectures online } \\
\text { More content is given, which is good because we can use when teaching }\end{array}$ \\
\hline
\end{tabular}


Work and learn at own pace More convenient to use eLearning allows you to take things at your own pace, discuss the issues and submit assignments easily - excellent

The major benefit of the eLearning activities was the students' utilisation of discussion boards. The majority of comments from students in both Human Movement and Health Education and Music Education were related to the stimulation of thought, discussion, debate and interaction via the online discussion boards. Students identified learning from other students' differing and broadly expressed opinions, as well as being enabled to more deeply contextualise and further analyse the content material and develop a deeper understanding of the material being covered. A second major theme arising from the student comments was the ability to easily organise and access the material being studied. Students repeatedly mentioned the eLearning process as being a convenient and efficient means of utilising the information. Finally, students' identified the valuable discussion board interactions with peers that were in an asynchronous environment. Participants commented on their communications with other students about timetabling issues, receiving ideas, information and moral support and communicating about how to best handle the course requirements.

It appears, therefore, that amongst these major themes are the following findings that eLearning helps students to: expand learning through other direct links; facilitate and motivate learning before class; tests knowledge and examines the students' stages of learning; provide a storage site for now and in the future; and provide a place for instant feedback from peers and teachers.

In this research study the students were also asked to rank the most important aspect of eLearning for their learning. The ranked list of perceived benefits is given below in Table 2 .

Table 2. eLearning activities, functions and aspects of elearning that the students ranked in order of the most helpful to student learning

\begin{tabular}{|c|c|}
\hline Ranking & Sample student comments \\
\hline 1 - Discussion boards & $\begin{array}{l}\text { posting ideas and getting feedback } \\
\text { it can be anonymous } \\
\text { other peoples' opinions }\end{array}$ \\
\hline 2 - Online lectures & $\begin{array}{l}\text { will help when it comes to study for an exam } \\
\text { when I couldn't attend the lectures }\end{array}$ \\
\hline $\begin{array}{l}3 \text { - Online learning materials and } \\
\text { links, readings }\end{array}$ & $\begin{array}{l}\text { extra information via links to online resources } \\
\text { ability to access documents, links and information enhanced my learning } \\
\text { course content online and links to online material }\end{array}$ \\
\hline 4 - Quizzes & $\begin{array}{l}\text { can see answers straight away } \\
\text { provide immediate feedback } \\
\text { useful reference for exam preparation }\end{array}$ \\
\hline 5 - Access & $\begin{array}{l}\text { available all the time } \\
\text { done in my own time }\end{array}$ \\
\hline 6 - Submitting assignments & confirmation of assignment submission \\
\hline 7 - Online response & $\begin{array}{l}\text { as an assessment } \\
\text { a new way of learning }\end{array}$ \\
\hline
\end{tabular}


The three most highly ranked features of eLearning were the usefulness of the asynchronous discussion boards; access to high quality online lecture notes; and access to various online learning materials. One student, however, commented that the eLearning activities were not particularly effective in helping her/him learn, as 'it is difficult to expect a student to study of their own accord if there is no assessable component'. This may be because the student perceived that the online eLearning component of the course was voluntary in nature and relied heavily on your motivation to learn rather than being motivated to learn by the teaching and learning environment.

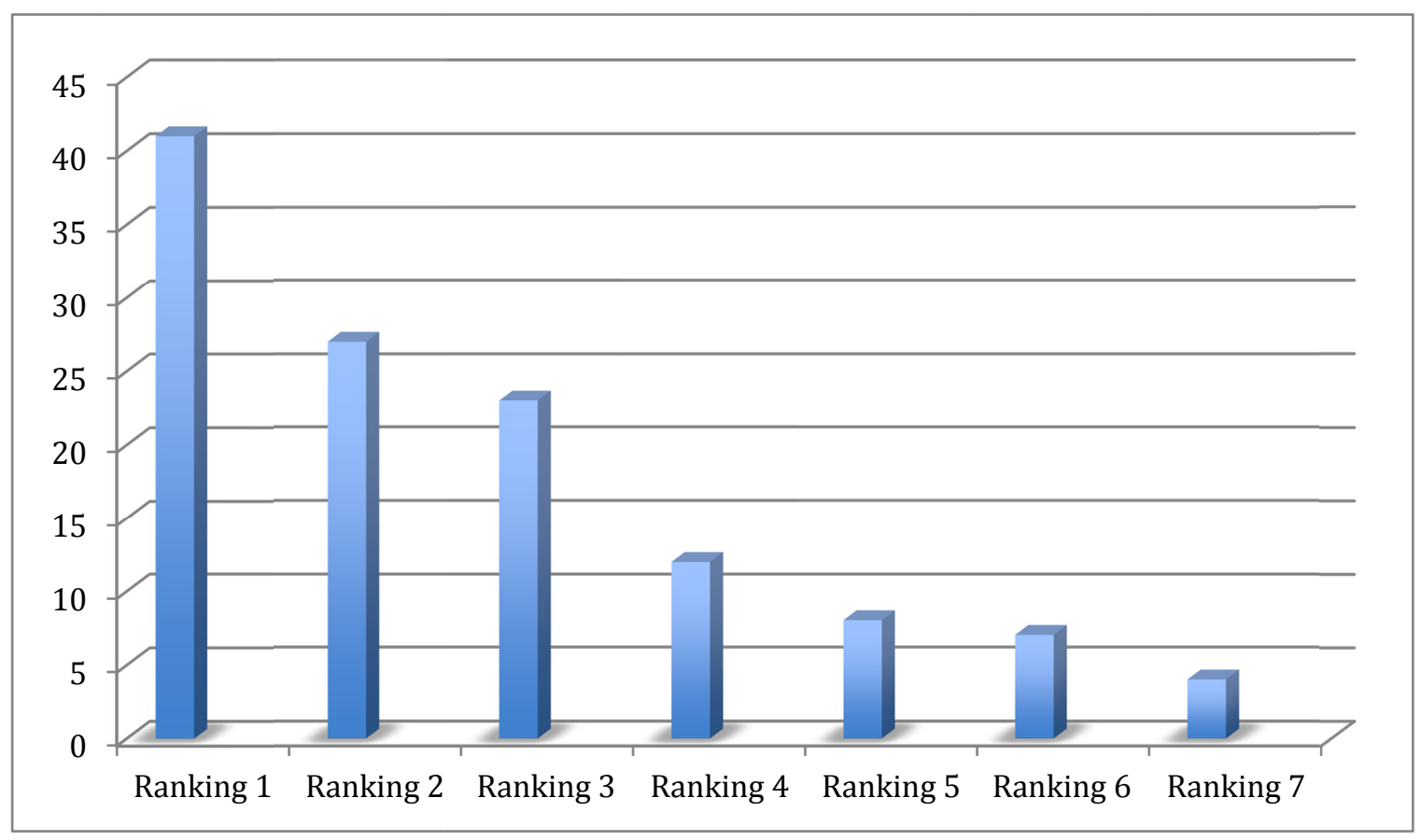

Figure 1. Students' enjoyment of learning

Figure 1 shows the number of students who ranked each perceived benefit of online learning listed in Table 2. It reveals how highly students ranked the discussion boards and the access to online learning materials, links and resources (including lectures).

\section{Discussion}

The study was designed as part of a sequence of studies over several years that investigated student perceptions and experiences of eLearning. As the major research question was to explore how students perceive the enhancement of their own learning and the benefits of using eLearning, the findings suggest that this cohort of undergraduates experience eLearning in much the same way as they experience other forms of online technology interactions with enjoyment. The challenge for the teacher is to find the greatest usefulness of the technology by appreciating the easy access for students to high quality online learning materials. In the study by Heirdsfield et al. (2011) they found that students" perceptions of the discussion boards were that encouraged teacher education students to think and increased 
their level of inquiry about the lecture content. They also found that students perceived the collaboration with peers increased their enjoyment of learning. This was not the students' opinion but rather their perception of learning through an online learning environment.

Interestingly, in the study reported here in this paper, the two different cohorts (from different campuses and different courses) reported similar perceptions of their eLearning experiences, suggesting that enjoyment of this form of learning is common amongst teacher education students. The specific findings of the study were that students perceived learning to be enjoyable and enhanced by use of eLearning and that it was the interaction on discussion boards that was integral to the students' perceived enhancement of learning. Student commented on how thoughts, ideas and knowledge via the online discussion board to be of value and they agreed that expressing of opinions freely on discussion boards encouraged them to further investigate the topic that was the focus of the discussion. The asynchronous online discussion between students where they interact and collaborate was similar to the theme that had been earlier noted in the study by Rowley and Tindall-Ford (2008) who found students' anxiety was alleviated by online discussion boards that students utilised whilst away from the campus on field placement. Long (2005) also noted that "using interactive engagement' for tertiary student learning produces higher learning gains (p.47).

Australian experts in teacher education (Groundwater-Smith et al., 2011; Whitton et al., 2010) note that that beginning teachers experience anxiety due to the challenges of the modern classroom. The findings of the current study concur, revealing that the students in this study agree that online learning reduced their anxiety and enhanced their learning by engaging with their similarly stressed peers via technology. Interaction with others, organisation of their learning, 24-hour access to lecture notes and resources (such as lesson plans, links to recommended sites etc.) and the flexibility that an eLearning provides, explained much of the perceived enhancement and reduction in anxiety among students in the current study. In addition, the interactive aspect of a blended learning environment was noted as a major theme from the participants and this result supports the previous literature (Ferfolja, 2008; Holstrom et al., 2007; Schick, 2003) who note the increasing popularity of blended learning environments in preparing pre-service teachers for the teaching profession. Other aspects of student learning may be explained by the personal experiences that eLearning fosters between peers. Themes found in this study that support how the students perceived enhancement of their own learning through the use of online learning were increased communication; easy access to lecturers and other students; the undertaking and submitting of online assessment tasks and the facilitation of learning before the face-to-face classes.

The strength of this study was in its ability to examine the same set of research criteria simultaneously between two separate cohorts of students who were matched for age and gender, but were studying on different campuses and in different content areas. This independent study design enabled the examination and comparison of any cross-curricular differences that may have arisen, and, in the current study, similarities were identified. However, it must be noted that this small study of 124 students is not necessarily representative of the whole student population of teacher education students in Australia. 


\section{Conclusion}

Limitations of the study include the lack of a "control" situation to counter possibility that it was online access on offer from our eLearning courses that enhanced the students' perceived learning. With an alternate control situation, we could have examined whether students would have satisfied their need for online interaction with other students in another way. Students may produce their own form of "online interaction and discussion" if it is not deliberately put in place by teaching staff, and this is a research question that could be investigated in a future study. Another limitation of our study is the lack of standardisation of the course content as the two cohorts of students in the current study were using different eLearning sites that were designed in different discipline areas, with different discussion board topics by different educational designers. Comparisons between more homogeneous groups using the same sites would have produced an aspect of reliability in the data that cannot be measured in this study. Although this is a limitation to the study, it can also be seen as strength as the students reported similar experiences of enhancement of their learning.

Future research could include measuring actual student learning achievement in order to objectively examine if there was a measurable change in student achievement as a result of the blended learning. This would enable the examination of the rellationship between perceived learning and actual learning. Finally, the views expressed by students in this study concur with recommendations from several researchers who challenge teacher educators to better utilise available technologies and to better design interactive teaching and learning environments where students can more readily engage in the pursuit of their own learning. Long and Holeton (2009), ask "how might we merge a culture of inquiry into teaching and learning with a culture of experimentation around new media technologies?" (p. 38). We, therefore, recommend that teacher educators should pursue eLearning strategies to achieve a shared teaching and learning goal in the $21^{\text {st }}$ century.

\section{References}

Akanbi, L. B. (2000). Enhancing Professional Experience through WebCT: a Model for preparing reading professionals. $21^{\text {st }}$ National Council of States. Miami, FL, November 2000.

Bass, R. (2009). New Media Technologies and the Scholarship of Teaching and Learning. Academic Commons. Retrieved January 7, 2009, from http://www.academiccommons.org/issue/january-2009

Bickford, D. J., \& Wright, D. J. (2006). Community: The Hidden Context for Learning in Learning Spaces (an Educause e-Book, Diana Oblinger, Ed.).

Bowles, M. C. (2004). Relearning to e-learn (electronic resource): strategies for electronic learning and knowledge. Carlton, Vic.: Melbourne University Press. http/search.informit.com.au.ezproxy1.library.usyd.edu.au

Dixon, R., Dixon, K., \& Siragusa, L. (2007). Individuals' perceptions of online environments: What adult learners are telling us. In ICT: Providing choices for learners and learning. 
Proceedings ascilite

http://www.ascilite.org.au/conferences/singapore07/procs/dixon.pdf

Ellis, R. A., Goodyear, P., O'Hara, A., \& Prosser, M. (2007). The University Student Experience of face-to-face and online discussions: coherence, reflection and meaning. ALT-J, 15(1), 83-97. http://dx.doi.org/10.1080/09687760601130057

Ferfolja, T. (2008). Building Teacher Capital in Pre-Service Teachers: Reflections on a New Teacher Education Initiative. Australian Journal of Teacher Education, 33(2), 68-84. http://dx.doi.org/10.14221/ajte.2008v33n2.5

Graff, M. (2006). The Importance of online community in student academic performance. The Electronic Journal of e-Learning, 4(2), 127-132.

Groundwater-Smith, S., Ewing, R., \& Le Cornu, R. (2011). Teaching Challenges and Dilemmas (4th Ed.). Southbank, Vic: Thomson.

Heirdsfield, A., Walker, S., Tambyah, M., \& Beutel, D. (2011). Blackboard As An Online Learning Environment: What Do Teacher Education Students And Staff Think? Australian Journal of Teacher Education, 36(7). http://dx.doi.org/10.14221/ajte.2011v36n7.4

Holstrom, L., Ruiz, D., \& Weller, G. (2007). A New View: reflection and student teacher growth through an epracticum model. E-Learning, 4(1), 5-14. http://dx.doi.org/10.2304/elea.2007.4.1.5

Long, P. D., \& Ehrmann, S. D. (2005). Future of the Learning Space: Breaking Out of the Box. EDUCAUSE Review, 40(4), 42-58.

Long, R. D., \& Holeton, R. (2009). Signposts of the Revolution? What We Talk about When We Talk about Learning Spaces. EDUCAUSE Review, 44(2), 36-49.

Merryfield, M. (2003). Like a Veil: Cross-cultural Experiential Learning Online. Contemporary Issues in Technology and Teacher Education, 3(2). Retrieved from $\mathrm{http} / / \mathrm{www}$.citejournal.org/vol3/iss2/social studies1.cfm

Murray-Harvey, R. (1999). Paper presented at the Colloquium in Field Based Education, Flinders University, Adelaide, Australia, 24-26 November, 1999.

NSW Institute of Teachers. (n.d.). Retrieved from www.nswiot.edu.au

O’Dea, J. A.,Yager, Z., \& Crawford, L. (2006). Enhancing course design and learning in blended environments: education students' attitudes towards and experiences of WebCT. Poster presentation at USyd Edfac Assessment and Learning Forum, June, 2006.

Pajo, P., \& Wallace, C. (2001). Barriers To The Uptake Of Web-based Technology by University Teachers. The Journal of Distance Education / Revue de l'Éducation à Distance, 16(1), 70-84.

Palmer, S., \& Holt, D. (2009). Staff and student perceptions of an online learning environment: Difference and development Australasian Journal of Educational Technology, 
25(3), 366-381.

Ramsden, P. (2003). Learning to Teach in Higher Education (2nd Edition). London: Routledge-Falmer.

Rowley, J., \& O'Dea, J. (2009). How do students perceive the enhancement of their own learning? A quantitative comparison of two Education faculties' experiences in building an online learning community for bachelor of Music Education and Bachelor of Education students. Conference proceedings 'Teacher education crossing borders: Cultures, contexts, communities and curriculum'. The annual conference of the Australian Teacher Education Association (ATEA), Albury, 28 June - 1 July.

Rowley, J. L., \& Tindall-Ford, S. (2008). Professional Experience and WebCT at the Sydney Conservatorium of Music. Synergy, 28, 14-21.

Schuck, S. (2003). Getting help from the outside: Developing a support network for beginning teachers. Journal of Educational Enquiry, 4(1), 49-67.

Taylor, J., Dunbar-Hall, P., \& Rowley, J. (2012). Music education students and ePortfolios: a case study in the 'digital natives' debate. Australasian Journal of Educational Technology, $28(8), 1362-1381$.

Whitton, D., Sinclair, C., Barker, K., Nanlohy, P. \& Nosworthy, M. (2010). Learning for teaching: teaching for learning (2nd ed.). Southbank, Vic.: Thomson.

\section{Copyright Disclaimer}

Copyright reserved by the authors.

This article is an open-access article distributed under the terms and conditions of the Creative Commons Attribution license (http://creativecommons.org/licenses/by/3.0/). 